Research Article

\title{
Liquiritin from Radix Glycyrrhizae Protects Cardiac Mitochondria from Hypoxia/Reoxygenation Damage
}

\author{
Vu Thi Thu $\mathbb{D}^{1,2}$ Ngo Thi Hai Yen ${ }^{1}{ }^{1}{ }^{1}$ and Nguyen Thi Ha Ly $\mathbb{D}^{3}$ \\ ${ }^{1}$ Center for Life Science Research, Faculty of Biology, VNU University of Science, Vietnam National University, 334 Nguyen Trai, \\ Hanoi, Vietnam \\ ${ }^{2}$ The Key Laboratory of Enzyme and Protein Technology, VNU University of Science, Vietnam National University, \\ Hanoi, Vietnam \\ ${ }^{3}$ National Institute of Medical Materials, Hanoi, Vietnam
}

Correspondence should be addressed to Vu Thi Thu; vtthu2015@gmail.com

Received 14 June 2021; Revised 9 July 2021; Accepted 24 July 2021; Published 9 August 2021

Academic Editor: Dang Quoc Thuyet

Copyright (c) $2021 \mathrm{Vu}$ Thi Thu et al. This is an open access article distributed under the Creative Commons Attribution License, which permits unrestricted use, distribution, and reproduction in any medium, provided the original work is properly cited.

Aims. The purpose of this study was to evaluate the protective effect of liquiritin (LIQ) from Radix Glycyrrhizae on cardiac mitochondria against hypoxia/reoxygenation (HR) injury. Methods. H9C2 cells were subject to the HR model. LIQ purified from Radix Glycyrrhizae (purity > 95\%) was administrated to reoxygenation period. Cell viability, mitochondrial mass, mitochondrial membrane potential, reactive oxygen species, and mitochondrial $\mathrm{Ca}^{2+}$ level were then assessed by using Cell Counting kit- 8 and suitable fluorescence probe kits. Results. LIQ administration remarkably reduced the rate of HR damage via increasing H9C2 cell viability level and preserving mitochondria after HR. Particularly, $60 \mu \mathrm{M}$ of LIQ posthypoxic treatment markedly reduced cell death in HR-subjected H9C2 cell groups $(p<0.05)$. Interestingly, posthypoxic treatment of LIQ significantly prevented the loss of mitochondrial membrane potential, the decrease in mitochondrial mass, the increase in reactive oxygen species production, and the elevation of mitochondrial $\mathrm{Ca}^{2+}$ level in HR-treated H9C2 cells. Conclusion. The present study provides for the first time the cardioprotective of LIQ posthypoxic treatment via reducing $\mathrm{H} 9 \mathrm{C} 2$ cell death and protecting cardiac mitochondria against HR damage.

\section{Introduction}

As the "powerhouse" and "apoptosis center" in myocytes, mitochondria have been described to play a key role in the pathogenesis of ischemic heart disease [1,2]. Mitochondrial dysfunction is disastrous for the heart and has been implicated in hypoxia/reoxygenation injury (HR) [3-6]. During hypoxia, electron transport chain activities are depressed as a result of damage to cardiolipin and an increased $\mathrm{H}^{+}$leak, thereby compromising mitochondrial membrane potential $(\Delta \Psi \mathrm{m})$ and ATP synthesis [1]. Upon reoxygenation, reintroduction of oxygen further compromises mitochondrial malfunction. Phenomena of the malfunctions include an alteration of $\Delta \Psi \mathrm{m}$ [7], an excessive generation of reactive oxygen species (ROS), a disruption of $\mathrm{Ca}^{2+}$ homeostasis [8], an opening of the permeability transition pore
$[9,10]$, and an initiating apoptosis [11]. As mitochondrial abnormality occurring in the reoxygenation period has been identified as a hallmark of ischemic heart disease, targeting mitochondrial protection during reperfusion can improve the recovery of contractile function $[4,12]$. On the other hand, preservation of mitochondrial function is essential to limit myocardial damage and subsequently suppresses the progression of ischemic heart disease. In this context, mitochondria are of increasing interest and concern in pharmaceutical and medical research of $\operatorname{HR}$ injury $[3,4,13]$. Among the possible mechanisms of cardioprotection, hypoxic postconditioning is one of the most effective mechanisms for protecting cardiomyocytes against HR damage via preventing the mitochondrial structure and function $[7,14]$, attenuating mitochondrial $\mathrm{Ca}^{2+}$ accumulation [7] as well as mitochondrial ROS generation $[15,16]$. 
In recent decades, there has been great progress in screening and identifying natural compounds to develop new drugs, which can be used to preserve mitochondrial integrity, limit oxidative stress, and subsequently improve cardiac function in $\operatorname{HR}[14,17,18]$. Of those, liquiritin (LIQ) is the main constituent of Radix Glycyrrhizae and has been proved to possess various pharmacological activities, such as anti-inflammatory, antioxidant, antiapoptosis, antibacteria [19], and anticancer properties [20-24]. It was previously reported that LIQ exerted protective effects against lipopolysaccharides-induced acute lung injury [25] and high fructose-induced myocardial fibrosis [26]. LIQ was able to resist human corneal endothelial cells apoptosis induced by oxybuprocaine [27] and to interfere with hypaconitine by affecting the CaM expression and $\mathrm{Cx} 43$ dephosphorylation in rat cardiac muscle in vivo [28]. The combinations of LIQ with other ingredients may also regulate the expression of calcium-regulated proteins to protect rat myocardial cells from damage [29]. Furthermore, extracts from Glycyrrhiza uralensis suppressed doxorubicin-induced apoptosis in H9C2 rat cardiac myoblasts [30] and protected the heart against doxorubicin-induced cardiotoxicity [31]. In fact, many traditional medicine formulas containing LIQ have been used to treat cardiovascular diseases, particularly ischemic heart diseases, such as Si-Miao-Yong-An decoction [32], Xuefu Zhuyu decoction [33], YangXinDingJi capsule [18], and ethanol extract of Jaeumganghwa-tang [34]. The studies showed that YangXinDingJi significantly relieved $\mathrm{HR}$ damage via increasing the survival of $\mathrm{H} 9 \mathrm{C} 2$ cardiomyocytes [33], inhibiting inflammatory cytokine expressions, reducing oxidative stress, and improving contractility in isolated rat cardiomyocytes [18]. Ethanol extract of Jaeumganghwa-tang is relatively more efficacious at protecting against oxidative stress-induced muscle cell death [34]. LIQ single treatment might be a potential agent against cerebral ischemia/reperfusion injury in mice by its antioxidant and antiapoptosis properties [20].

Though LIQ in combination with other constituents or ingredients possessing a potential protective effect on various models was demonstrated, the research evaluating the single treatment of LIQ on the ischemic heart disease model is rare. Up to now, the bioactivity of LIQ in the HR-induced H9C2 model has not been explored yet. Therefore, the present study reports for the first time the cardioprotective effects of LIQ from Radix Glycyrrhizae against HR injuries by targeting mitochondria.

\section{Materials and Methods}

The details of each experiment are available in Supplementary Material.

2.1. Ethics Statement. All experimental procedures were reviewed and approved by VNU University of Science.

2.2. Isolation of Liquiritin (LIQ) from Radix Glycyrrhizae (Liquorice Root). Dried roots of Radix Glycyrrhizae (5 kg) were extracted with $96 \%$ ethanol (EtOH) under reflux three times. After filtration, the combined EtOH extract was removed under vacuum to obtain a crude extract, which was then suspended in distilled water and partitioned with ethyl acetate (EtOAc) to yield an EtOAc extract $(185.0 \mathrm{~g})$. The EtOAc extract was subjected to silica gel column chromatography (CC) and eluted with hexane-EtOAc-methanol (5: $1: 0.1, \mathrm{v} / \mathrm{v} / \mathrm{v}), \mathrm{CHCl}_{3}$-acetone-methanol $(3: 1: 0.1, \mathrm{v} / \mathrm{v} / \mathrm{v})$, and $\mathrm{CHCl}_{3}$-methanol-water $(3: 1: 0.1, \mathrm{v} / \mathrm{v} / \mathrm{v})$ to obtain three main fractions (E1-E3). Fraction E3 (24.5 g) was separated on reversed-phase $\mathrm{C}_{18}\left(\mathrm{RP}-\mathrm{C}_{18}\right) \mathrm{CC}$ and eluted with methanol-water $(20-70 \% \mathrm{MeOH}, \mathrm{v} / \mathrm{v})$ to afford subfractions (E3A, E3B, E3C). Subfraction E3B was further purified by RP-C ${ }_{18}$ CC with methanol-water $(40: 60 \mathrm{v} / \mathrm{v})$ as an eluted solvent to yield compound LIQ $(441.0 \mathrm{mg})$. The spectral data of LIQ was completely identical with those of LIQ published in the reference [35] (see Supplemental material 1, Table S11 and Figures S1.1-S1.7); therefore, the compound LIQ was determined.

2.3. Cell Culture. Rat cardiomyocytes, H9C2 cells, obtained from the American Type Culture Collection (ATCC; Rockville, MD, USA), were maintained in Dulbecco's Modified Eagle's Medium (DMEM; Gibco, Invitrogen, Carlsbad, CA, USA) supplemented with $100 \mu \mathrm{g} / \mathrm{ml}$ of penicillin/streptomycin and $10 \%$ fetal bovine serum (FBS; Invitrogen) at $37^{\circ} \mathrm{C}$ with $5 \% \mathrm{CO}_{2}$. The culture medium was changed every 2-3 days. The cells were subjected to HR model, cell viability assay, and mitochondrial relating assays.

2.4. Hypoxia/Reoxygenation In Vitro Model and Treatments. H9C2 cells were cultured and subjected to the HR model as described previously [14]. For hypoxic culture, cells were cultured in serum-free low-glucose DMEM at $37^{\circ} \mathrm{C}, 95 \% \mathrm{~N}_{2}$, $5 \% \mathrm{CO}_{2}$, and $2 \% \mathrm{O}_{2}$. For reoxygenated culture, cells were cultured under normal conditions following hypoxic culture. After incubation in hypoxic conditions for $6 \mathrm{~h}, \mathrm{H} 9 \mathrm{C} 2$ cells were then transferred to reoxygenation for $24 \mathrm{~h}$. For the HR-stimulated group, H9C2 cells were reoxygenated without any treatment. For all treatment groups, at the time of reoxygenation, $\mathrm{H} 9 \mathrm{C} 2$ cells were separately treated with liquiritin (LIQ, $1.2 \div 600 \mu \mathrm{M}$ ) or NecroX-5 (NEC, $10 \mu \mathrm{M}$, serves as positive drug control). The stocks of LIQ and NEC were prepared in DMSO and the final concentration of DMSO in the cultured medium was about $0.1 \%$. Cells were cultured under normal conditions without any treatment served as a normal control group.

2.5. Cell Viability Assay. Cell viability was assessed by the mitochondrial-dependent reduction of 2-(2-methoxy-4nitrophenyl)-3-(4-nitrophenyl)-5-(2, 4-disulfophenyl)-2Htetrazolium, monosodium salt (WST-8) to WST-8 formazan (CCK-8, Dojindo) as described in our last study [14]. For each group, H9C2 cells were seeded in triplicate into 96-well culture plates at a density of $10^{4}$ cells/well for $24 \mathrm{~h}$. The optimal dose $(60 \mu \mathrm{M})$ of LIQ was initially determined and chosen for assessing its cardioprotective effects against HR (see Supplementary material 2, Table S2-1, Figures S2-1 and 
S2-2). By the end of the experimental periods, the cell groups were further incubated for $1-4 \mathrm{~h}$ with CCK- 8 solution. The absorbance value indicating cell viability was measured at $450 \mathrm{~nm}$ using a microplate reader (Microplate Reader, Molecular Devices, USA). The number of living cells in each well was expressed as a value relative to the normal control. Experiments were repeated 6 times.

2.6. Measurement of Mitochondrial Mass. Mitochondrial mass was evaluated based on what was previously mentioned [36]. H9C2 cells were seeded at a density of $10^{4}$ cells/well in 96-well black, glass-bottom plates (CAT. 33196, SPL) or confocal dishes (CAT. 100350, SPL). After HR, NEC, and LIQ60 treatment, H9C2 cells were stained with either MitoTracker Green $(0.1 \mu \mathrm{M}$, ex/em: $490 / 516 \mathrm{~nm}$, Invitrogen, USA) or MitoTracker Red $(0.1 \mu \mathrm{M}$, ex/em: $581 / 644 \mathrm{~nm}$, Invitrogen, USA) at $37^{\circ} \mathrm{C}$ for $30 \mathrm{~min}$ at room temperature and then washed twice with PBS. The changes in fluorescence intensity reflecting mitochondrial mass are independently assessed by a microplate reader or the ApoTome Fluorescence Microscope (Zeiss, ApoTome). In the assay using the microplate, the mitochondrial mass in each well was expressed as a percentage value relative to the normal control. The cell images were captured using the ApoTome and reconstructed from individual tiles (X:6, Y:9) using ZEN Blue 2.5 software (Carl Zeiss). The MitoTracker intensities (arbitrary unit, AU) of individual cells in captured images were measured. Experiments were performed in triplicate.

\subsection{Measurement of Mitochondrial Membrane Potential.} To measure $\Delta \Psi \mathrm{m}, \mathrm{H} 9 \mathrm{C} 2$ cells were seeded at a density of $10^{4}$ cells/well in 96-well black, glass-bottom plates (CAT. 33196, SPL) or confocal dishes (CAT. 100350, SPL). After being subjected to different conditions, cells were stained with $0.1 \mu \mathrm{M}$ tetramethylrhodamine ethyl ester (TMRE; excitation/emission: 535/570 nm, Invitrogen, USA) for $30 \mathrm{~min}$ at room temperature. Next, they were washed twice with PBS before measuring fluorescence intensity using a microplate reader or ApoTome as previously mentioned [14]. The ApoTome-captured images were reconstructed from individual tiles (X:6, Y:9) using ZEN Blue 2.5 software (Carl Zeiss). The TMRE fluorescence intensities (AU) of individual cells in captured images were measured. In the assay using the microplate, the total TMRE intensity in each well was expressed as a percentage value relative to the normal control. Experiments were performed in triplicate.

2.8. Measurement of ROS Production. ROS production was evaluated following a previous report [14]. H9C2 cells were seeded at a density of $10^{4}$ cells/well in 96-well black, glassbottom plates (CAT. 33196, SPL) or confocal dishes (CAT. 100350, SPL). After being subjected to different conditions, cells were stained with $5 \mu \mathrm{M} \quad 2^{\prime}, 7^{\prime}$-dichlorodihydrofluorescein-diacetate (CM- $\mathrm{H}_{2} \mathrm{DCFDA}$; ex/em $485 / 525 \mathrm{~nm}$, Invitrogen, $\mathrm{USA}$ ) at $37^{\circ} \mathrm{C}$ for $30 \mathrm{~min}$ at room temperature to detect changes in mitochondrial ROS levels. After washing twice with PBS 1X, the different fluorescence intensities were measured using the microplate reader. The total $\mathrm{H}_{2}$ DCFDA intensity in each well was expressed as a percentage value relative to the normal control. Experiments were performed in triplicate. In another experimental set, $\mathrm{H}_{2}$ DCFDA-stained cells were captured using the ApoTome and the images were then reconstructed from individual tiles (X:6, Y:9) using ZEN Blue 2.5 software (Carl Zeiss). The fluorescence intensities (AU) of individual cells in captured images were measured. Experiments were performed in triplicate.

2.9. Measurement of Mitochondrial $\mathrm{Ca}^{2+}$. Mitochondrial $\mathrm{Ca}^{2+}$ levels were assed using Rhod-2 AM (5 $\mu \mathrm{M}$, ex/em: 533/ $576 \mathrm{~nm}$, Invitrogen, USA) as previously described [7]. H9C2 cells were seeded at a density of $10^{4}$ cells/well in 96-well black, glass-bottom plates (CAT. 33196, SPL) or confocal dishes (CAT. 100350, SPL) and subjected to the different conditions. After that, the samples were then stained with Rhod-2 AM and then washed twice with PBS 1X. The total intensity value indicating mitochondrial $\mathrm{Ca}^{2+}$ was measured by a microplate reader. The different cell groups were also captured using the ApoTome. The images were reconstructed from individual tiles (X:6, Y:9) using ZEN Blue 2.5 software (Carl Zeiss). The Rhod-2 AM intensities of individual cells in captured images were measured. Experiments were performed in triplicate.

2.10. Statistical Analysis. Data are presented as mean$\mathrm{s} \pm$ standard error of the mean (SEM). Differences between the two groups were evaluated by one-way analysis of variance (ANOVA) and the comparison over time was tested with a two-way ANOVA and Turkey test. Differences with a $p$ value $\leq 0.05$ were considered significant.

\section{Results and Discussions}

3.1. Liquiritin (LIQ) from Radix Glycyrrhizae. Liquiritin (LIQ) was extracted and purified from the root of Radix Glycyrrhizae based on the bioassay and chromatographic methods described above. The isolated LIQ compound was identified and had the following characteristics: light yellow amorphous powder, purity $>95 \%$ (high performance liquid chromatography), and electrospray ionization mass spectrometry: $417.2[\mathrm{M}-\mathrm{H}]^{-}, 453.1[\mathrm{M}+\mathrm{Cl}]^{-}$(negative), 419.0 $[\mathrm{M}+\mathrm{H}]^{+}$(positive) (Figure 1, Supplemental Material 1). The obtained results showed that Radix Glycyrrhizae consists of approximately $0.088 \mathrm{mg} / \mathrm{g}$ of the LIQ component, which is consistent with previous reports $[35,37]$.

\subsection{LIQ Enhanced H9C2 Cell Viability against HR Injury.} As described above, H9C2 cells were subjected to different conditions and the cell viabilities were measured using the CCK-8 kit (Figure 2). The results showed that the viabilities were dramatically reduced in the HR-exposed cells compared to normal cells (Figures 2(a) and 2(b), $p<0.01$ ). In this study, NEC was used as the positive control and showed its efficacy in protecting the cells against $\mathrm{HR}$ with a similar value referred to our previous publication [7]. In this study, LIQ at 
<smiles></smiles>

Figure 1: Structure of liquiritin (LIQ) from Radix Glycyrrhizae.

doses of $1.2,12,60,120$, and $300 \mu \mathrm{M}$ strongly prevented the H9C2 cell death from HR. In contrast, LIQ at a dose of $600 \mu \mathrm{M}$ showed its toxicity to the cardiomyocytes under normal and HR conditions (see Supplemental material 2, Table S2.1, Figures S2.1 and S2.2).

Though the cell viability of other LIQ-treated groups (LIQ at doses of $1.2,12,60,120$, and $300 \mu \mathrm{M}$ ) were comparably lower than NEC, supplementation of LIQ during reoxygenation period still significantly minimized the cell death compared to those in $\operatorname{HR}(66.27 \pm 1.53 \%$, $p<0.05)$. Interestingly, among HR-exposed groups, the highest $\mathrm{H} 9 \mathrm{C} 2$ viability was presented in the LIQ posthypoxic treatment at a dose of $60 \mu \mathrm{M}$ (LIQ60). In the LIQ60 group, the cell viability was dramatically increased up to $92.06 \pm 2.09 \%$ of normal control $(100 \%)$. It was reported that LIQ increased cell viability via its anti-inflammatory [38], antioxidant, and antiapoptosis activity [20, 23]. The current results further confirmed the safety of LIQ indicated in the previous publication [39]. LIQ has no significant effect on cell viability or hepatotoxicity with different treatments of concentration and duration, suggesting the safety of this compound [39]. However, another study documented that LIQ at the concentrations of $0.1 \div 100 \mu \mathrm{M}$ exerted no cytoprotective effect against cadmium-induced toxicity, whereas liquiritigenin, the hydrolysis product of LIQ or constitutes of Radix Glycyrrhizae extract, exerted the cytoprotective effects [40]. Thus, the present data showed that the most effective dose of LIQ against HR damage was about $60 \mu \mathrm{M}$. Based on that, we decided to choose LIQ posthypoxic treatment at a dose of $60 \mu \mathrm{M}$ for further evaluation.

\subsection{LIQ Preserved Mitochondrial Mass under HR Injury.} MitoTracker Green and MitoTracker Red are fluorescent probes, accumulating in mitochondria, and have been used to assess mitochondrial mass or content [36]. To take a closer look at the LIQ roles in mitochondrial mass, we ran the MitoTrackers based experiments and obtained the results as presented in Figure 3. The quantitative results showed either the intensity of individual cells which have been acquired by ApoTome fluorescence microscope (Figures 3(a), 3(b), 3(d), and $3(\mathrm{e})$ ) or the total intensity of wells in the microplate reader (Figures 3(c), 3(f)).

The results showed that the total mitochondrial contents determined by labeling with these two markers were strongly varied under the subjected conditions. We observed that the total MitoTracker Green fluorescence intensity reflecting mitochondrial mass was significantly decreased in HR groups compared to those in the control group $(p<0.05)$. Treatment of either NEC or LIQ60 was able to diminish the HR injury regarding the recovery of mitochondrial mass with the brighter green and red color and with higher intensity values compared to those in HR. The total MitoTracker Green intensity and the total MitoTracker Red values in NEC and LIQ60 groups were significantly higher than those in the nontreated HR group. Additionally, the mitochondrial contents in the subjected groups obtained by quantifying the fluorescent signals per cell were varied in different conditions (Figure 3(a), 3(b), 3(d), and 3(e)). Thus, among HR groups, the lowest mitochondrial contents were presented in HR. The HR groups supplied with either NEC or LIQ60 possessed a higher cell density with the brighter fluorescent color and higher fluorescent values (AU) representing the higher mitochondrial contents. Interestingly, the effects of LIQ on mitochondrial mass, determined in parallel and labelled with the mitochondriaspecific MitoTrackers, are almost similar to those in NEC. Here, the obtained results were consistent with the previous study [41], and NEC protected cardiomyocytes via preserving PGC1 $\alpha$, the well-known regulator of mitochondrial mass. Therefore, it seems that the preservation effects of LIQ on mitochondrial content constitute a cellular response to compensate for the mitochondriatargeted damage, which was documented in another disease [23]. It was reported that oxidative stress-induced cardiovascular diseases were involved in mitochondrial malfunction and mitochondrial mass. Under the oxidative condition produced by tert-butyl hydroperoxide, the increase in mitochondrial mass in $\mathrm{H} 9 \mathrm{C} 2$ cells was linked with the mitochondrial dysfuntion [42]. In addition, total fluorescence intensity values could further confirm the survival cell numbers in each group as demonstrated above (Figure 2). Taken together, a hypoxia-induced decrement in mitochondrial mass associated with a less alive cardiomyocyte numbers could be eliminated by LIQ treatment at the dose of $60 \mu \mathrm{M}$.

Given the fact that the ideas of using MitoTracker probes are controversial, in addition to employing these two probes for the purpose of mitochondrial mass, the mitochondrial loading of these dyes shows some sensitivity to $\Delta \psi \mathrm{m}$ [36]. The previous study had also suggested the potential use of MitoTracker to assess the alteration of $\Delta \psi \mathrm{m}$ [43]. Another research had suggested that to interpret appropriate results, technical considerations and parallel complementary assays should be applied [44]. Despite LIQ being effectively targeted on mitochondria mass, the underlying mechanism of mitochondrial function and mitochondrial integrity remained unclear. We assumed that LIQ60 might not only preserve mitochondrial mass but also maintain mitochondrial integrity and function. To test the hypothesis, we carried out the mitochondrial membrane potential assay as described in the next section.

3.4. LIQ Posthypoxic Treatment Prevented the Collapse of $\triangle \Psi m$ from HR Injury. Mitochondrial membrane potential is an important index to assess mitochondrial function. A 

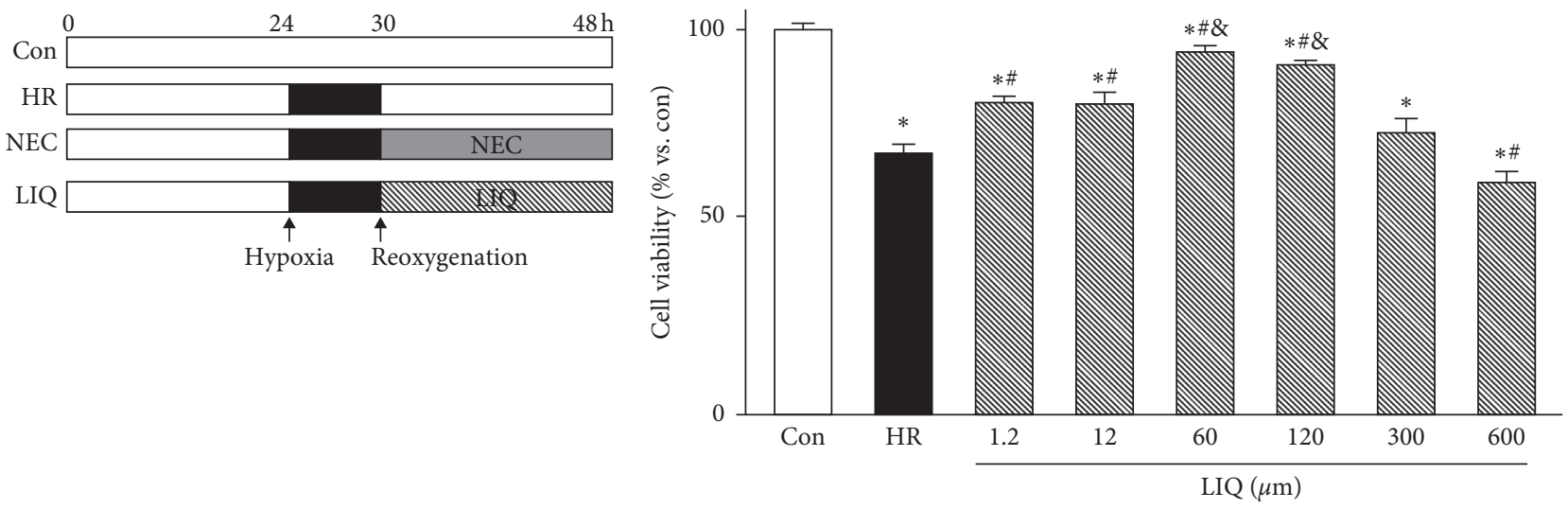

(a)

(b)

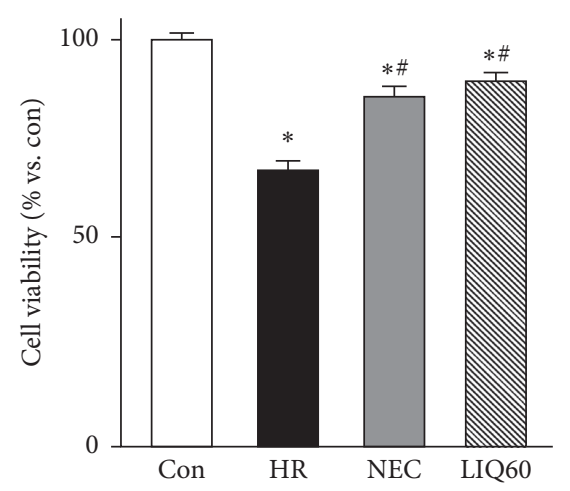

(c)

FIGURE 2: Experimental design and cell viability assay. (a) HR model and LIQ treatment. ((b)-(c)) The graph indicates H9C2 cell viability under different conditions and treatments. Con: normal control; HR: hypoxia/reoxygenation; LIQ: HR + liquiritin (LIQ); NEC: HR + NecroX-5 $(10 \mu \mathrm{M})$; LIQ60: HR + LIQ at a dose of $60 \mu \mathrm{M} ;{ }^{*} p<0.05 \mathrm{vs.} \mathrm{Con;}{ }^{\#} p<0.05 \mathrm{vs}$. HR; ${ }^{*} p<0.05$ vs. LIQ at doses of $1.2,12,300$, and $600 \mu \mathrm{M}, n=6$ for each group.

collapse of $\Delta \Psi \mathrm{m}$ reflects a mitochondrial malfunction and consequently leads to cell death [45]. To further assess the role of LIQ60 on mitochondrial function, TMRE was used, according to the manufacturer's instructions. The mitochondrial membrane potential of the experimental groups is presented in Figure 4.

Our data showed that HR significantly induced mitochondrial dysfunction compared to control $(p<0.01)$. Similar to NEC, supplementation of LIQ60 markedly prevented the collapse of $\Delta \Psi \mathrm{m}$ against HR injury $(p<0.01)$. There was an insignificant difference in $\Delta \Psi \mathrm{m}$ value, described by TMRE intensities, between the NEC group and LIQ60 group (Figure 4(c), $p>0.05$ ). In all groups, the total TMRE intensities were quite matched with the TMRE intensity mean values of individual cells in the presentative images (Figure 4(c)). In consistence with our previous report [7], NEC strongly enhanced mitochondrial function against HR. The present finding suggested that LIQ at a dose of $60 \mu \mathrm{M}$ showed its ability to prevent the collapse of $\Delta \Psi \mathrm{m}$ in HR-stimulated H9C2. However, regardless of cardiomyocytes, LIQ was able to accelerate the apoptosis via altering $\Delta \Psi \mathrm{m}$ in rheumatoid arthritis pathological condition [46]. LIQ significantly decreased viability and induced apoptosis in the hepatocellular carcinoma cell line by decreasing mitochondrial membrane potential [47]. Here, LIQ was applied during reoxygenation period, so we assumed that the better preservation of mitochondrial membrane potential is closely associated with this compound's ability in modulating mitochondrial mass and eliminating oxidative stress as well as mitochondrial $\mathrm{Ca}^{2+}$ overload.

3.5. LIQ Decreased Mitochondrial Oxidative Stress Induced by HR Injury. The ability of LIQ60 to stabilize the integrity of mitochondrial membrane was further shown in examining ROS production. Here, ROS levels in $\mathrm{H} 9 \mathrm{C} 2$ were determined using $\mathrm{CM}-\mathrm{H}_{2} \mathrm{DCFDA}$ (Figure 5).

As shown in Figure 5, ROS levels were highly increased under HR conditions compared to those in normal control conditions $(p<0.05)$. Notably, treatment of either NEC or LIQ was able to significantly decrease the HR-induced ROS levels $(p<0.01)$. The $\mathrm{CM}-\mathrm{H}_{2} \mathrm{DCFDA}$ intensity mean value of individual cells was almost similar to that counted in total fluorescence intensity. Interestingly, the ability to suppress ROS generation of LIQ seems to be equal to NEC $(p>0.05)$. In fact, NEC is well known as the active compound playing multiple roles and targeting multiple cellular signals. In particular, NEC was previously described as the strong mitochondrial oxidative stress scavenger combating the overproduction of ROS $[7,48]$. Thus, the present finding could reconfirm the antioxidative 


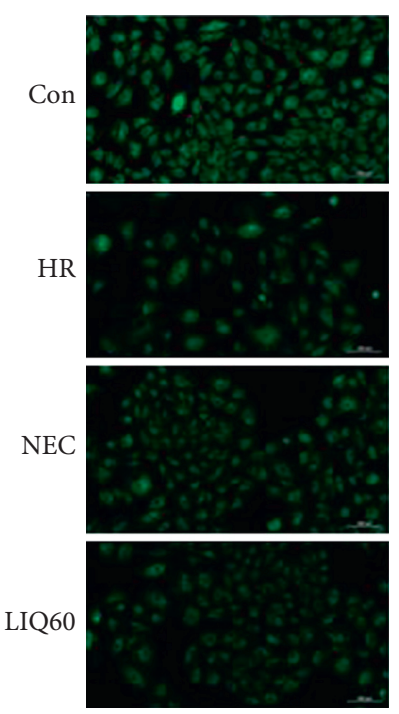

(a)

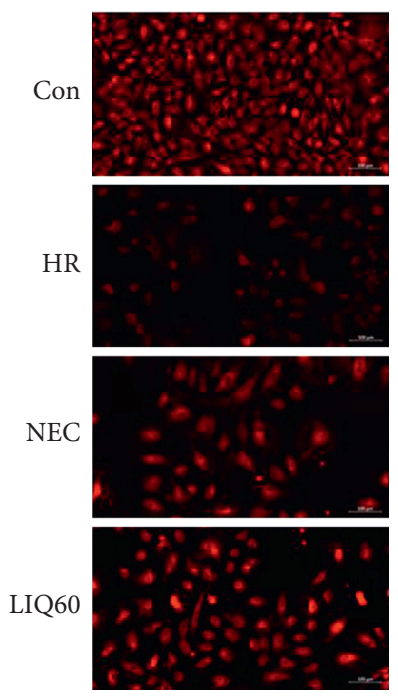

(d)
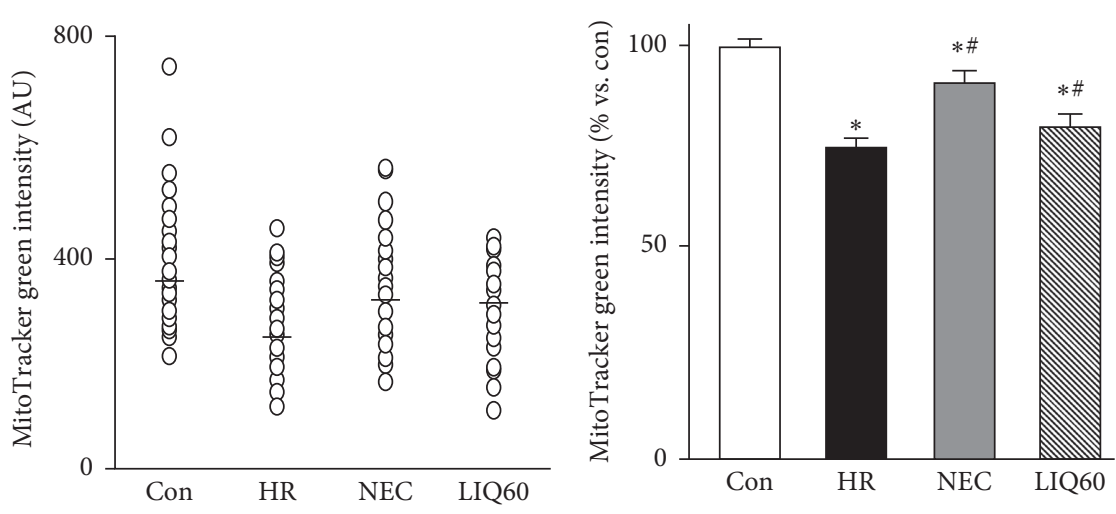

(b)
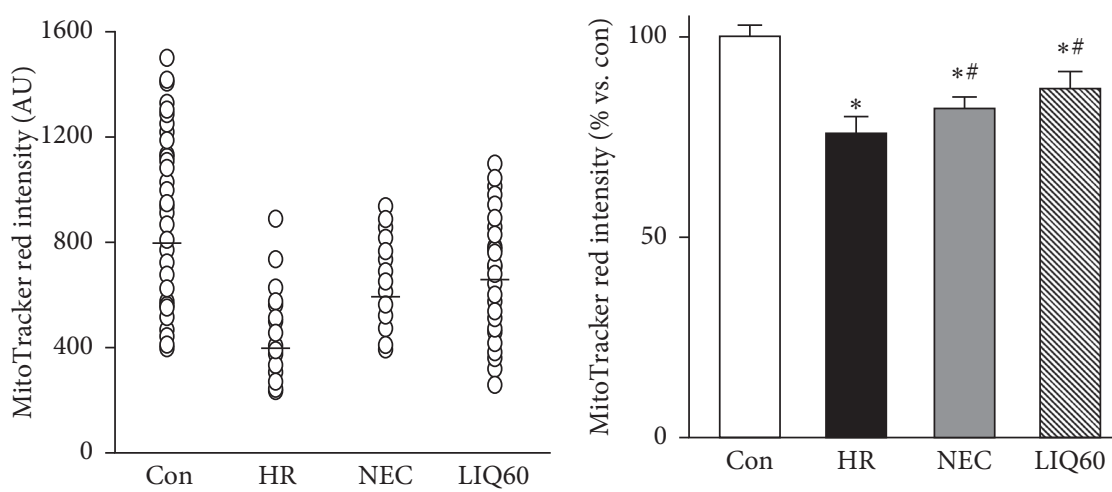

(e)

(f)

FIgUre 3: Mitochondrial mass in H9C2 cells subjected to different treatments. (a) Representative images of H9C2 cells stained with MitoTracker Green. (b) The graph indicates MitoTracker green fluorescence intensity per cell $(O$, open circle) of the representative images. (c) The graph indicates the total MitoTracker green intensity. (d) Representative images of H9C2 cells stained with MitoTracker red. (e) The graph indicates MitoTracker red fluorescence intensity per cell $(\mathrm{O}$, open circle) of the representative images. (f) The graph indicates the total MitoTracker red intensity. AU: arbitrary unit; Con: normal control; HR: hypoxia/reoxygenation; NEC: HR + NecroX-5; LIQ60: HR + LIQ at a dose of $60 \mu \mathrm{M}$; ${ }^{*} p<0.05$ vs. Con; ${ }^{\#} p<0.05$ vs. HR; $n=3$; scale bar $100 \mu \mathrm{m}$.

stress of LIQ reported in the previous studies [49, 50]. Earlier studies had also demonstrated the LIQ effectively decreased ROS production in hepatocellular carcinoma cell line [47], skin cells [39], and neuron cells [20]. It was reported that the increase in ROS production was associated with the loss of cardiolipin in lethal cell or the disruption of mitochondrial membrane integrity under ischemia injuries [7, 51]. In this study, the obtained data proved the role of LIQ in protecting H9C2 cells against HR injuries. Thus, the efficacy in maintaining mitochondrial membrane structure and function of LIQ could reinforce for the role of Radix Glycyrrhizae extract on protecting cardiomyocytes [17], possibly by targeting the main source of oxidative stress.
3.6. LIQ Attenuated Mitochondrial Calcium Level in HR Injury. As a consequence of HR damage, an imbalance in $\mathrm{Ca}^{2+}$ homeostasis could lead to abnormal contraction of cardiomyocytes, consequently leading to heart malfunction $[52,53]$. Of those, mitochondrial $\mathrm{Ca}^{2+}$ overload could contribute to hypercontraction of cells upon reoxygenation. We found that mitochondrial $\mathrm{Ca}^{2+}$ level in HR groups was markedly increased in HR groups compared to the control group. That increase was pronounced in the HR-stimulated H9C2 cells without treatment of either NEC or LIQ60. Supplementation of NEC and LIQ strongly suppressed the elevation of mitochondrial $\mathrm{Ca}^{2+}$ level $(p<0.05)$. Interestingly, similar to NEC, HR-induced mitochondrial $\mathrm{Ca}^{2+}$ 


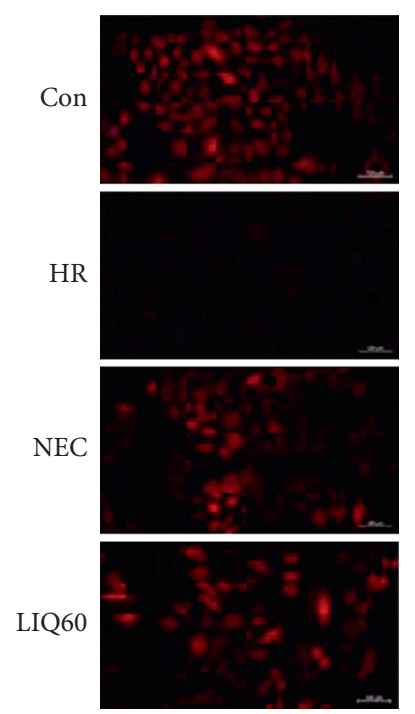

(a)

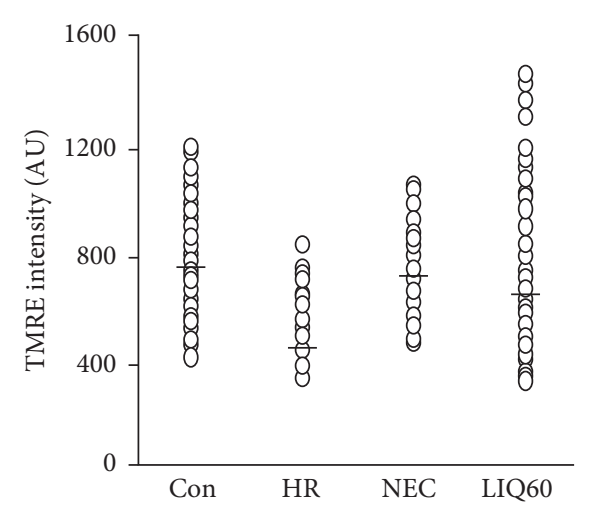

(b)

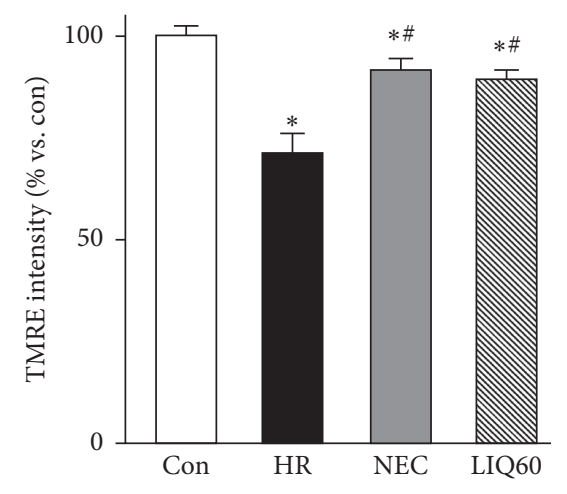

(c)

FIGURE 4: Mitochondrial function in H9C2 cells subjected to different treatments. (a) Representative images of H9C2 cells stained with tetramethylrhodamine ethyl ester (TMRE). (b) The graph indicates fluorescence intensity per cell $(\mathrm{O}$, open circle) of the representative images. (c) The graph indicates the total TMRE intensity; AU: arbitrary unit; Con: normal control; HR: hypoxia/reoxygenation; NEC: HR + NecroX-5; LIQ60: HR + LIQ at a dose of $60 \mu \mathrm{M}$; ${ }^{*} p<0.01$ vs. Con; ${ }^{\#} p<0.05$ vs. HR; $n=3$; scale bar $100 \mu \mathrm{m}$.

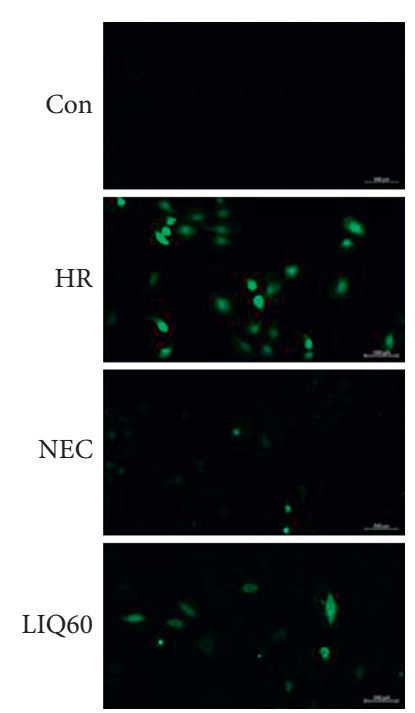

(a)

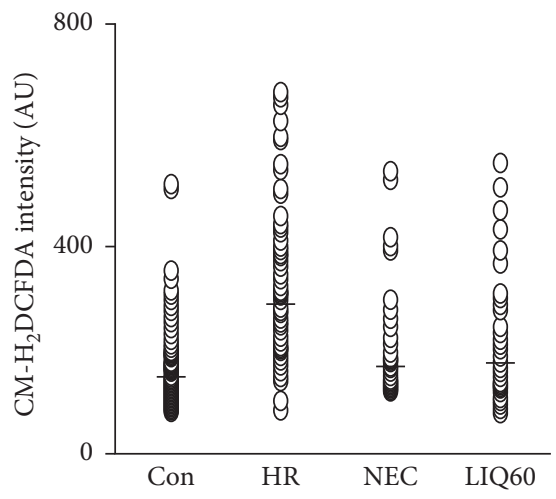

(b)

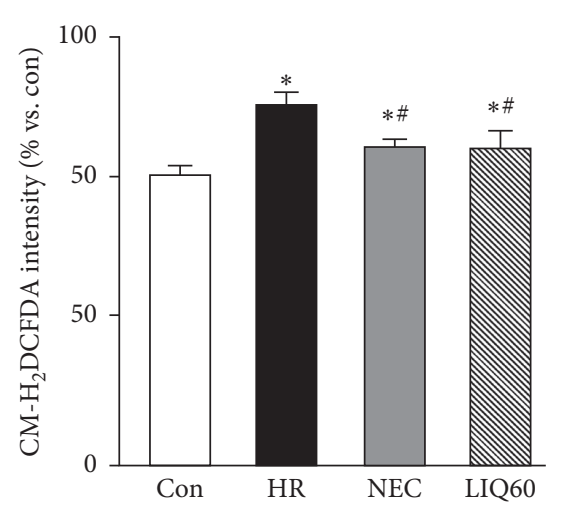

(c)

Figure 5: Mitochondrial oxidative stress in H9C2 cells subjected to different treatments. (a) Representative images of H9C2 cells stained with 5-(and-6)-chloromethyl-2', $7^{\prime}$-dichlorodihydrofluorescein diacetate, acetyl ester (CM- $\left.\mathrm{H}_{2} \mathrm{DCFDA}\right)$. (b) The graph indicates fluorescence intensity per cell (O, open circle) of the representative images. (c) The graph indicates the total CM- $\mathrm{H}_{2} \mathrm{DCFDA}$ intensity; AU: arbitrary unit; Con: normal control; HR: hypoxia/reoxygenation; NEC: HR + NecroX-5; LIQ60: HR + LIQ at a dose of $60 \mu \mathrm{M}$; ${ }^{*} p<0.05$ vs. Con; ${ }^{\#} p<0.05$ vs. HR; $n=3 \div 5$; scale bar $100 \mu \mathrm{m}$.

increase was strongly attenuated in the LIQ60 group compared with the HR group (Figure 6, $p<0.05$ ).

The total Rhod-2 AM intensity (Figure 6(c)) was consistent with the mean Rhod-2 AM intensity value (in AU) of individual myocardiocytes in the representative images of control, HR, NEC, and LIQ60 (Figures 6(a) and 6(b)). Notably, treatment of either NEC or LIQ markedly diminished the HR-induced mitochondrial $\mathrm{Ca}^{2+}$ alteration. As previously suggested, the high mitochondrial $\mathrm{Ca}^{2+}$ level in the $\mathrm{HR}$ group finally caused hypercontracture and cardiac cell death; however, NEC treatment dramatically prevented HR-induced $\mathrm{Ca}^{2+}$ overload, hypercontracture, and cardiac cell death [7]. The observations had suggested that mitochondrial $\mathrm{Ca}^{2^{+}}$plays a crucial role in mediating cell death at the first few minutes of reoxygenation as well as during this prolonged period $[7,10]$. Of the HR injuries, the reciprocal interactions between mitochondrial $\mathrm{Ca}^{2+}$ induced 


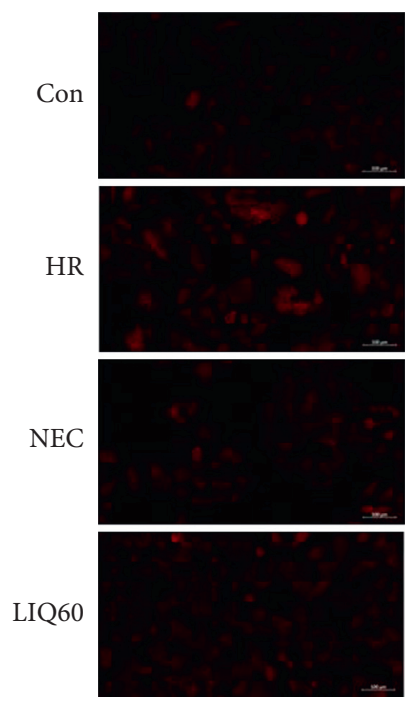

(a)

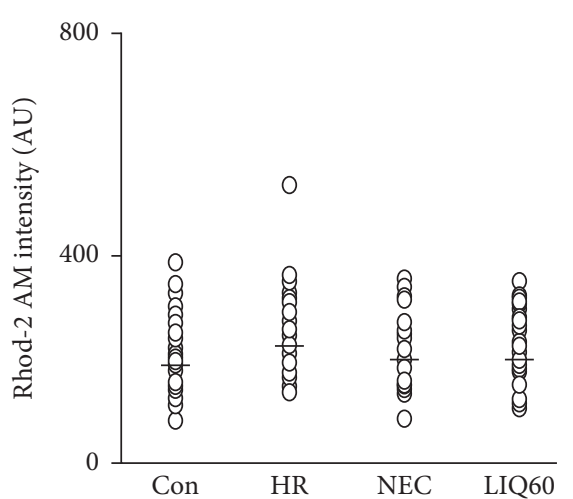

(b)

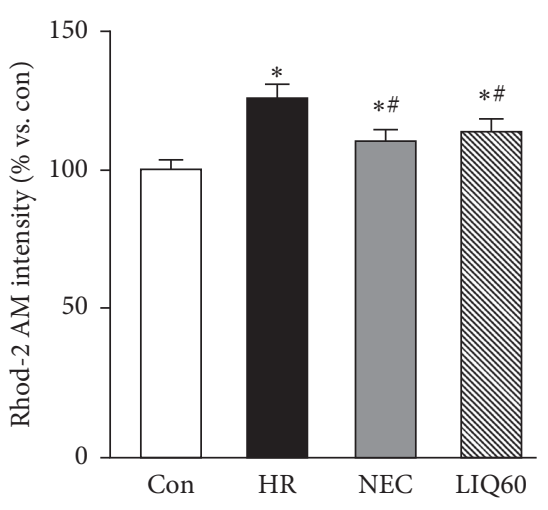

(c)

Figure 6: Mitochondrial calcium level in H9C2 cells subjected to different treatments. (a) Representative images of H9C2 cells stained with Rhod-2 AM. (b) The graph indicates fluorescence intensity per cell $(\mathrm{O}$, open circle) of the representative images. (c) The graph indicates the total Rhod-2 AM intensity; AU: arbitrary unit; Con: normal control; HR: hypoxia/reoxygenation; NEC: HR + NecroX-5; LIQ60: HR + LIQ at a dose of $60 \mu \mathrm{M}$; ${ }^{*} p<0.05$ vs. Con; ${ }^{\#} p<0.05$ vs. HR; $n=3$; scale bar $100 \mu \mathrm{m}$.

ROS overproduction and ROS modulated $\mathrm{Ca}^{2+}$ overload had been documented. As evidenced above, the cytoprotective effect of LIQ60 could be due to the mitochondrial ROS scavenging activity. Moreover, the effects of LIQ on $\mathrm{Ca}^{+}$were evidenced in various conditions. In a very recent report, LIQ was presented as a novel inhibitor of transient receptor potential cation channel 1 and transient receptor potential ion channel 1 , the $\mathrm{Ca}^{2+}$ relating channels in lung inflammation injury [25]. LIQ also ameliorated $\mathrm{Ca}^{2+}$ overload in the model of glutamate-induced cell damage in differentiated pheochromocytoma cells [54]. Additionally, LIQ was able to lower intracellular $\mathrm{Ca}^{2+}$ in Phytophthora capsici [55]. In this study, although the modulation of LIQ60 on mitochondrial calcium uniporter in stabilizing $\mathrm{Ca}^{2+}$ level was not analyzed yet, the trend and its end effect on this ion could further prove the protective role of LIQ60 on cardiac mitochondria.

\section{Conclusion}

To the best of our knowledge, this is the first study investigating the effect of LIQ on cardiac mitochondria against HR damage. Our results indicated that LIQ effectively increased H9C2 survival, preserved mitochondrial mass, prevented the collapse of $\Delta \Psi \mathrm{m}$, decreased the ROS elevation, and attenuated the overload of mitochondrial $\mathrm{Ca}^{2+}$. The pilot data might help clarify the myocardial protection role of LIQ against HR injury targeting mitochondria. The new role of LIQ might bring new hopes and potentials for drug development.

\section{Data Availability}

The underlying data supporting the results and the details of each experiment are available in the Supplementary Material.

\section{Conflicts of Interest}

The authors report no conflicts of interest.

\section{Acknowledgments}

The authors thank Nguyen Phuong Thao, Pham Thi Bich, Le Thanh Long, Nguyen Lai Thanh, and To Thanh Thuy for help and support in this project. They also thank Professor Phan Tuan Nghia, Professor Han Jin, and Professor Kim Hyoung Kyu for their invaluable guidance for the work. This work was supported by the Vietnam National Foundation for Science and Technology Development (NAFOSTED) under the Grand number 106-YS.06-2016.23.

\section{Supplementary Materials}

Supplementation material 1 (S1): Isolation of liquiritin (LIQ) from Radix Glycyrrhizae (liquorice root) (RG). Dried roots of liquorice root $(5 \mathrm{~kg})$ were extracted with $96 \%$ ethanol $(\mathrm{EtOH})$ under reflux three times (each $20 \mathrm{~L}$ ). After filtration, the combined EtOH extract was removed under vacuum to obtain a crude extract, which was then suspended in distilled water and partitioned with ethyl acetate (EtOAc) to yield an EtOAc extract $(185.0 \mathrm{~g})$. The EtOAc extract was subjected to silica gel column chromatography (CC) and eluted with hexane-EtOAc-methanol $(5: 1: 0.1, \mathrm{v} / \mathrm{v} / \mathrm{v})$, $\mathrm{CHCl}_{3}$-acetone-methanol $(3: 1: 0.1, \mathrm{v} / \mathrm{v} / \mathrm{v})$, and $\mathrm{CHCl}_{3}$ methanol-water $(3: 1: 0.1, \mathrm{v} / \mathrm{v} / \mathrm{v})$ to obtain three main fractions (E1-E3). Fraction E3 (24.5 g) was separated on reversed-phase $\mathrm{C}_{18}\left(\mathrm{RP}-\mathrm{C}_{18}\right) \mathrm{CC}$ and eluted with methanolwater $(20-70 \% \mathrm{MeOH}, \mathrm{v} / \mathrm{v})$ to afford three subfractions (E3A, E3B, E3C). Subfraction E3B was further purified by

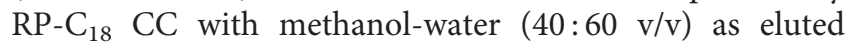
solvent to yield compound LIQ (441.0 mg). Compound LIQ: 
yellow powder; mp. $210-212^{\circ} \mathrm{C}$; UV (MeOH) $\lambda_{\max } 217,275$, $311 \mathrm{~nm}$; IR $\nu_{\max }\left(\mathrm{cm}^{-1}\right): 3429$ (hydroxy), 3329, 2911, 2077, 1607 (carbonyl), 1511, 1446, 1376, 1290, 1233, 1118, 1081, 1044, 997, 889, 834, 632, 531; APCI-MS: $m / z$ 417.2 [M - H] $]^{-}$, $453.1 \quad[\mathrm{M}+\mathrm{Cl}]^{-}$(negative), $419.0 \quad[\mathrm{M}+\mathrm{H}]^{+}$(positive); $\mathrm{C}_{21} \mathrm{H}_{22} \mathrm{O}_{9} ;{ }^{1} \mathrm{H}-\mathrm{NMR}\left(500 \mathrm{MHz}, \mathrm{CD}_{3} \mathrm{OD}\right): \delta_{\mathrm{H}} 7.75(1 \mathrm{H}, \mathrm{d}$, $J=9.0 \mathrm{~Hz}, \mathrm{H}-5), 7,46\left(2 \mathrm{H}, \mathrm{d}, J=9.0 \mathrm{~Hz}, \mathrm{H}-2^{\prime}, \mathrm{H}-6^{\prime}\right), 7.16$ $\left(2 \mathrm{H}, \mathrm{d}, J=8.5 \mathrm{~Hz}, \mathrm{H}-3^{\prime}, \mathrm{H}-5^{\prime}\right), 6.52(1 \mathrm{H}, \mathrm{dd}, J=9.0,2.5 \mathrm{~Hz}$, $\mathrm{H}-6), 6.39(1 \mathrm{H}, \mathrm{d}, J=2.5 \mathrm{~Hz}, \mathrm{H}-8), 5.47(1 \mathrm{H}, \mathrm{dd}, J=13.0$, $2.5 \mathrm{~Hz}, \mathrm{H}-2), 4.96\left(1 \mathrm{H}, \mathrm{d}, J=7.0 \mathrm{~Hz}, \mathrm{H}-1^{\prime \prime}\right), 3.91(1 \mathrm{H}, \mathrm{dd}$, $\left.J=12.0,2.0 \mathrm{~Hz}, \mathrm{H}-6^{\prime \prime} \mathrm{a}\right), 3.71(1 \mathrm{H}, \mathrm{dd}, J=12.0,5.5 \mathrm{~Hz}$, H-6"b), 3.40-3.50 (4H, m, H-2" $\left.{ }^{\prime \prime} \mathrm{H}-3^{\prime \prime}, \mathrm{H}-4^{\prime \prime}, \mathrm{H}-5^{\prime \prime}\right), 3.06$ $(1 \mathrm{H}, \mathrm{dd}, J=17.0,13.0 \mathrm{~Hz}, \mathrm{H}-3 \mathrm{a}), 2.75(1 \mathrm{H}, \mathrm{dd}, J=17.0$, $2.5 \mathrm{~Hz}, \mathrm{H}-3 \mathrm{~b}) ;{ }^{13} \mathrm{C}-\mathrm{NMR}\left(125 \mathrm{MHz}, \mathrm{CD}_{3} \mathrm{OD}\right): \delta_{\mathrm{C}} 193.2(\mathrm{C}-$ 4), 166.8 (C-7), 165.4 (C-9), $159.2\left(\mathrm{C}-4^{\prime}\right), 134.4\left(\mathrm{C}-1^{\prime}\right), 129.9$ (C-5), $128.8\left(\mathrm{C}-2^{\prime}, \mathrm{C}^{\prime} 6^{\prime}\right), 117.8\left(\mathrm{C}-3^{\prime}, \mathrm{C}-5^{\prime}\right), 115.0$ (C-10), 111.8 (C-6), 103.9 (C-8), $102.2\left(\mathrm{C}-1^{\prime \prime}\right), 80.7$ (C-2), 78.2 (C$\left.5^{\prime \prime}\right), 78.0\left(\mathrm{C}-3^{\prime \prime}\right), 74.9\left(\mathrm{C}-2^{\prime \prime}\right), 71.4\left(\mathrm{C}-4^{\prime \prime}\right), 62.5\left(\mathrm{C}-6^{\prime \prime}\right), 45.0$ (C-3). The spectral data of LIQ was completely identical with those of liquiritin published in the reference [35] (see Table S1.1, Figure S1.1-7); therefore, the compound LIQ was determined to be liquiritin. Table S1.1: NMR data of compound LIQ and liquiritin. Figure S1.1: UV-VIS spectrum of compound LIQ. Figure S1.2: IR spectrum of compound LIQ. Figure S1.3: APCI-MS spectrum of compound LIQ. Figure S1.4: ${ }^{1} \mathrm{H}-\mathrm{NMR}\left(500 \mathrm{MHz}, \mathrm{CD}_{3} \mathrm{OD}\right)$ spectrum of compound LIQ. Figure S1.5: ${ }^{13} \mathrm{C}-\mathrm{NMR}\left(125 \mathrm{MHz}, \mathrm{CD}_{3} \mathrm{OD}\right)$ spectrum of compound LIQ. Figure S1.6: DEPT spectrum of compound LIQ. Figure S1.7: HPLC chromatogram of LIQ. Supplemental material 2 (S2): Cellular toxicity. For each group, H9C2 cells were seeded in triplicate into 96-well culture plates at a density of $10^{4}$ cells per well for $24 \mathrm{~h}$. For testing the cellular toxicity of LIQ, the H9C2 cells was continuously kept in culture medium supplemented LIQ (at dose of $1.2 \div 600 \mu \mathrm{M}$ ) for $24 \mathrm{~h}$ at $37^{\circ} \mathrm{C}$ with $5 \% \mathrm{CO}_{2}$. In vitro cytotoxicity to LIQ was analyzed by the CCK- 8 assay as described in our last study [56]. The absorbance value indicating cell viability was measured at $450 \mathrm{~nm}$ using a microplate reader. The number of living cells in each well was expressed as a value relative to the normal control. Experiments were repeated at least 4 times. The cell viability of H9C2 in normal control conditions with and without LIQ supplementation and the $\mathrm{IC}_{50}$ value of LIQ were demonstrated in Figure S2.1. Optimum dose of LIQ. We measured protective effect of LIQ on HR-exposed H9C2 cells. For each group, H9C2 cells were seeded in triplicate into 96-well culture plates at a density of $10^{4}$ cells per well for $24 \mathrm{~h}$. Cells were subjected to hypoxia for $6 \mathrm{~h}$ prior to adding different dose of LIQ $(1.2 \div 300 \mu \mathrm{M})$ or NEC $(10 \mu \mathrm{M})$ to culture media during $24 \mathrm{~h}$ reoxygenation. The H9C2 cells of normal control group were cultured in normal incubation chamber for all experimental period. The cell viability under different conditions was analyzed by the CCK-8 assay as described in our last study [56]. Cell viability was assessed by the mitochondrial-dependent reduction of 2-(2-methoxy-4-nitrophenyl)-3-(4-nitrophenyl)-5-(2, 4disulfophenyl)-2H-tetrazolium, monosodium salt (WST-8) to WST-8 formazan (Cell Counting Kit-8, CCK-8, Dojindo) as described in our last study [56]. The absorbance value indicating cell viability was measured at $450 \mathrm{~nm}$ using a microplate reader (Microplate Reader, Molecular Devices, USA). The number of living cells in each well was expressed as a value relative to the normal control. Experiments were repeated at least 3 times. The optimal dose of LIQ in HRsubjected H9C2 model was $60 \mu \mathrm{M}$ and it was chosen for further experimental assays (Table S2.1, Figure S2.2). Table S2.1: H9C2 cell viability under different LIQ concentrations. Figure S2.1: Cell viability. The graphs indicate H9C2 cell viability after being treated with liquiritin (LIQ) at the doses of $0 \div 600 \mu \mathrm{M}$ (left) and $\mathrm{IC}_{50}(\mu \mathrm{M}$, right) of LIQ in normal control condition. ${ }^{*} p<0.05$ vs. LIQ-nontreated group; $n=4 \div 6$ for each group. Figure S2.2: The graph indicates H9C2 cell in different conditions. Con: normal control; HR: hypoxia/reoxygenation; LIQ: HR + liquiritin (LIQ); NEC: HR + NecroX-5 $(10 \mu \mathrm{M}) ;{ }^{*} p<0.05$ vs. Con; ${ }^{\#} p<0.05$ vs. HR; ${ }^{\&} p<0.05$ vs. LIQ at doses of $1.2,12,300$, and $600 \mu \mathrm{M}, n=6$ for each group. (Supplementary Materials)

\section{References}

[1] M. Suleiman, A. P. Halestrap, and E. J. Griffiths, "Mitochondria: a target for myocardial protection," Pharmacology \& Therapeutics, vol. 89, no. 1, pp. 29-46, 2001.

[2] J. Wang, S. Toan, and H. Zhou, "New insights into the role of mitochondria in cardiac microvascular ischemia/reperfusion injury," Angiogenesis, vol. 23, no. 3, pp. 299-314, 2020.

[3] A. K. S. Camara, M. Bienengraeber, and D. F. Stowe, "Mitochondrial approaches to protect against cardiac ischemia and reperfusion injury," Frontiers in Physiology, vol. 2, 2011.

[4] R. A. J. Smith, R. C. Hartley, H. M. Cochemé, and M. P. Murphy, "Mitochondrial pharmacology," Trends in Pharmacological Sciences, vol. 33, no. 6, pp. 341-352, 2012.

[5] J. Wang, S. Toan, and H. Zhou, "Mitochondrial quality control in cardiac microvascular ischemia-reperfusion injury: new insights into the mechanisms and therapeutic potentials," Pharmacological Research, vol. 156, Article ID 104771, 2020.

[6] H. Zhou, S. Toan, P. Zhu, J. Wang, J. Ren, and Y. Zhang, "DNA-PKcs promotes cardiac ischemia reperfusion injury through mitigating BI-1-governed mitochondrial homeostasis," Basic Research in Cardiology, vol. 115, no. 2, p. 11, 2020.

[7] V. T. Thu, H.-K. Kim, L. T. Long et al., "NecroX-5 prevents hypoxia/reoxygenation injury by inhibiting the mitochondrial calcium uniporter," Cardiovascular Research, vol. 94, no. 2, pp. 342-350, 2012.

[8] A. P. Halestrap, "Calcium, mitochondria and reperfusion injury: a pore way to die," Biochemical Society Transactions, vol. 34, pp. 232-237, 2006.

[9] J.-S. Kim, Y. Jin, and J. J. Lemasters, "Reactive oxygen species, but not $\mathrm{Ca}^{2+}$ overloading, trigger $\mathrm{pH}$ - and mitochondrial permeability transition-dependent death of adult rat myocytes after ischemia-reperfusion," American Journal of Physiology-Heart and Circulatory Physiology, vol. 290, no. 5, 2006.

[10] D. Garcia-Dorado, M. Ruiz-Meana, J. Inserte, A. RodriguezSinovas, and H. M. Piper, "Calcium-mediated cell death during myocardial reperfusion," Cardiovascular Research, vol. 94, no. 2, pp. 168-180, 2012.

[11] A. E. Greijer and E. van der Wall, "The role of hypoxia inducible factor 1 (HIF-1) in hypoxia induced apoptosis," Journal of Clinical Pathology, vol. 57, no. 10, pp. 1009-1014, 2004.

[12] K. D. Garlid, A. D. T. Costa, C. L. Quinlan, S. V. Pierre, and P. Dos Santos, "Cardioprotective signaling to mitochondria," 
Journal of Molecular and Cellular Cardiology, vol. 46, no. 6, pp. 858-866, 2009.

[13] J. Wang and H. Zhou, "Mitochondrial quality control mechanisms as molecular targets in cardiac ischemia-reperfusion injury," Acta Pharmaceutica Sinica B, vol. 10, no. 10, pp. 1866-1879, 2020.

[14] V. T. Thu, N. T. H. Yen, N. H. Tung, P. T. Bich, J. Han, and H. K. Kim, "Majonoside-R2 extracted from Vietnamese ginseng protects $\mathrm{H} 9 \mathrm{C} 2$ cells against hypoxia/reoxygenation injury via modulating mitochondrial function and biogenesis," Bioorganic \& Medicinal Chemistry Letters, vol. 36, Article ID $127814,2021$.

[15] V. T. Thu, H. K. Kim, S. H. Ha et al., "Glutathione peroxidase 1 protects mitochondria against hypoxia/reoxygenation damage in mouse hearts," Pflügers Archiv-European Journal of Physiology, vol. 460, no. 1, pp. 55-68, 2010.

[16] M. Saotome, "Transient opening of mitochondrial permeability transition pore by reactive oxygen species protects myocardium from ischemia/reperfusion injury," American Journal of Physiology-Heart and Circulatory Physiology, vol. 296, no. 4, 2009.

[17] H. Ding, "Clematichinenoside (AR) attenuates hypoxia/ reoxygenation-induced $\mathrm{H} 9 \mathrm{C} 2$ cardiomyocyte apoptosis via a mitochondria-mediated signaling pathway," Molecules, vol. 21, no. 6, 2016.

[18] M. Liu, "Mechanisms underlying the cardioprotection of YangXinDingJi capsule against myocardial ischemia in rats. Evidence-Based Complementary and Alternative Medicine," vol. 2020, Article ID 8539148, 16 pages, 2020.

[19] J. He, L. Chen, D. Heber, W. Shi, and Q.-Y. Lu, “Antibacterial compounds fromGlycyrrhizauralensis," Journal of Natural Products, vol. 69, no. 1, pp. 121-124, 2006.

[20] Y.-X. Sun, Y. Tang, A.-L. Wu et al., "Neuroprotective effect of liquiritin against focal cerebral ischemia/reperfusion in mice via its antioxidant and antiapoptosis properties," Journal of Asian Natural Products Research, vol. 12, no. 12, pp. 10511060, 2010.

[21] J.-Y. Yu, J. Ha, K.-M. Kim, Y.-S. Jung, J.-C. Jung, and S. Oh, "Anti-inflammatory activities of licorice extract and its active compounds, Glycyrrhizic acid, Liquiritin and Liquiritigenin, in BV2 cells and mice liver," Molecules, vol. 20, no. 7, pp. 13041-13054, 2015.

[22] Y. Nakatani, A. Kobe, M. Kuriya et al., "Neuroprotective effect of liquiritin as an antioxidant via an increase in glucose-6phosphate dehydrogenase expression on B65 neuroblastoma cells," European Journal of Pharmacology, vol. 815, pp. 381390, 2017.

[23] X. Li, X. Qin, J. Tian et al., "Liquiritin protects PC12 cells from corticosterone-induced neurotoxicity via regulation of metabolic disorders, attenuation ERK1/2-NF- $\kappa$ B pathway, activation Nrf2-Keap1 pathway, and inhibition mitochondrial apoptosis pathway," Food and Chemical Toxicology, vol. 146, Article ID 111801, 2020.

[24] F. Wei, X. Jiang, H.-Y. Gao, and S.-H. Gao, "Liquiritin induces apoptosis and autophagy in cisplatin (DDP)-resistant gastric cancer cells in vitro and xenograft nude mice in vivo," International Journal of Oncology, vol. 51, no. 5, pp. 1383-1394, 2017.

[25] Z. Liu, P. Wang, S. Lu et al., "Liquiritin, a novel inhibitor of TRPV1 and TRPA1, protects against LPS-induced acute lung injury," Cell Calcium, vol. 88, Article ID 102198, 2020.

[26] Y. Zhang, L. Zhang, Y. Zhang, J.-J. Xu, L.-L. Sun, and S.-Z. Li, "The protective role of liquiritin in high fructose-induced myocardial fibrosis via inhibiting NF- $\kappa$ B and MAPK signaling pathway," Biomedicine \& Pharmacotherapy, vol. 84, pp. 1337-1349, 2016.

[27] D. Li and P. Zhang, "Protective effect and molecular mechanism of liquiritin on oxybuprocaine-induced apoptosis of human corneal endothelial cells," Experimental and therapeutic medicine, vol. 15, no. 4, pp. 3432-3438, 2018.

[28] M. Yi, W. Peng, X. Chen, J. Wang, and Y. Chen, "Effect of hypaconitine combined with liquiritin on the expression of calmodulin and connexin 43 in rat cardiac muscle in vivo," Journal of Pharmacy and Pharmacology, vol. 64, no. 11, pp. 1654-1658, 2012.

[29] Y. Zhang, L. Yu, W. Jin et al., "Reducing toxicity and increasing efficiency: aconitine with liquiritin and glycyrrhetinic acid regulate calcium regulatory proteins in rat myocardial cell," African Journal of Traditional, Complementary and Alternative Medicines, vol. 14, no. 4, pp. 69-79, 2017.

[30] H. J. Choi, M. R. Seon, S. S. Lim, J.-S. Kim, H. S. Chun, and J. H. Y. Park, "Hexane/ethanol extract ofGlycyrrhiza uralensisLicorice suppresses doxorubicin-induced apoptosis in $\mathrm{H} 9 \mathrm{c} 2$ rat cardiac myoblasts," Experimental Biology and Medicine, vol. 233, no. 12, pp. 1554-1560, 2008.

[31] L. Zhang, Y. Yang, L. Yu, Y. Wang, L. Liu, and X. Fan, "Cardioprotective effects of Glycyrrhiza uralensis extract against doxorubicin- induced toxicity," International Journal of Toxicology, vol. 30, no. 2, pp. 181-189, 2011.

[32] X.-Y. Chen, X.-H. Chen, L. Li et al., "Deciphering the effective combinatorial components from Si-Miao-Yong-An decoction regarding the intervention on myocardial hypertrophy," Journal of Ethnopharmacology, vol. 271, Article ID 113833, 2021.

[33] X. Shi, H. Zhu, Y. Zhang, M. Zhou, D. Tang, and H. Zhang, "XuefuZhuyu decoction protected cardiomyocytes against hypoxia/reoxygenation injury by inhibiting autophagy," BMC Complementary and Alternative Medicine, vol. 17, no. 1, p. 325, 2017.

[34] Y. S. Kim, H. J. Yuk, and D. S. Kim, "Effect of jakyakgamchotang extracts on $\mathrm{H}_{2} \mathrm{O}_{2}$-induced $\mathrm{C} 2 \mathrm{C} 12$ myoblasts," Molecules, vol. 26, no. 1, p. 215, 2021.

[35] A. M. El-Gerby and A. Awad, "Anti-tumor, antioxidant and antimicrobial and the phenolic constituents of Glycyrrhiza glabra," Organic Chemistry: An Indian Journal, vol. 10, no. 10, pp. 410-416, 2014.

[36] D. Puleston, "Detection of mitochondrial mass, damage, and reactive oxygen species by flow cytometry," Cold Spring Harbor Protocols, vol. 9, 2015.

[37] J. Liu, "Studies on the identification of constituents in ethanol extract of Radix Glycyrrhizae and their anti-primary hepatoma cell susceptibility," Journal of Chemistry, vol. 2014, Article ID 134379, 5 pages, 2014.

[38] P. Zhou, F. Hua, X. Wang, and J.-L. Huang, "Therapeutic potential of IKK- $\beta$ inhibitors from natural phenolics for inflammation in cardiovascular diseases," Inflammopharmacology, vol. 28, no. 1, pp. 19-37, 2020.

[39] X. Q. Li, "Liquiritin suppresses UVB-induced skin injury through prevention of inflammation, oxidative stress and apoptosis through the TLR4/MyD88/NF- $\kappa$ B and MAPK/ caspase signaling pathways," International Journal of Molecular Medicine, vol. 42, no. 3, pp. 1445-1459, 2018.

[40] S. C. Kim, S. H. Byun, C. H. Yang, C. Y. Kim, J. W. Kim, and S. G. Kim, "Cytoprotective effects of Glycyrrhizae radix extract and its active component liquiritigenin against cadmium-induced toxicity (effects on bad translocation and cytochrome c-mediated PARP cleavage)," Toxicology, vol. 197, no. 3, pp. 239-251, 2004. 
[41] V. T. Thu, H. K. Kim, L. T. Long et al., "NecroX-5 protects mitochondrial oxidative phosphorylation capacity and preserves PGC1 $\alpha$ expression levels during hypoxia/reoxygenation injury," The Korean Journal of Physiology \& Pharmacology, vol. 20, no. 2, pp. 201-211, 2016.

[42] C. Luo, Y. Li, H. Wang et al., "Mitochondrial accumulation under oxidative stress is due to defects in autophagy," Journal of Cellular Biochemistry, vol. 114, no. 1, pp. 212-219, 2013.

[43] W. Pendergrass, N. Wolf, and M. Poot, "Efficacy of MitoTracker Green? and CMXrosamine to measure changes in mitochondrial membrane potentials in living cells and tissues," Cytometry, vol. 61, no. 2, pp. 162-169, 2004.

[44] S. W. Perry, J. P. Norman, J. Barbieri, E. B. Brown, and H. A. Gelbard, "Mitochondrial membrane potential probes and the proton gradient: a practical usage guide," BioTechniques, vol. 50, no. 2, pp. 98-115, 2011.

[45] L. D. Zorova, V. A. Popkov, E. Y. Plotnikov et al., "Mitochondrial membrane potential," Analytical Biochemistry, vol. 552, pp. 50-59, 2018.

[46] K.-F. Zhai, H. Duan, C.-Y. Cui et al., "Liquiritin from Glycyrrhiza uralensis attenuating rheumatoid arthritis via reducing inflammation, suppressing angiogenesis, and inhibiting MAPK signaling pathway," Journal of Agricultural and Food Chemistry, vol. 67, no. 10, pp. 2856-2864, 2019.

[47] J.-R. Wang, T.-Z. Li, C. Wang et al., "Liquiritin inhibits proliferation and induces apoptosis in HepG2 hepatocellular carcinoma cells via the ROS-mediated MAPK/AKT/NF- $\kappa \mathrm{B}$ signaling pathway," Naunyn-Schmiedeber's Archives of Pharmacology, vol. 393, no. 10, pp. 1987-1999, 2020.

[48] H. J. Kim, S. Y. Koo, B.-H. Ahn et al., "NecroX as a novel class of mitochondrial reactive oxygen species and ONOO-scavenger," Archives of Pharmacal Research, vol. 33, no. 11, pp. 1813-1823, 2010.

[49] I. J. Dela Pena, "The psychopharmacological activities of Vietnamese ginseng in mice: characterization of its psychomotor, sedative-hypnotic, antistress, anxiolytic, and cognitive effects," Journal of Ginseng Research, vol. 41, 2016.

[50] N. T. Huong, "In vitro antioxidant activity of Vietnamese ginseng saponin and its components," Biological and Pharmaceutical Bulletin, vol. 21, no. 9, pp. 978-981, 1998.

[51] G. Paradies, G. Petrosillo, M. Pistolese, N. Di Venosa, A. Federici, and F. M. Ruggiero, "Decrease in mitochondrial complex I activity in ischemic/reperfused rat heart," Circulation Research, vol. 94, no. 1, pp. 53-59, 2004.

[52] H.-X. Xu, S.-M. Cui, Y.-M. Zhang, and J. Ren, "Mitochondrial $\mathrm{Ca}^{2+}$ regulation in the etiology of heart failure: physiological and pathophysiological implications," Acta Pharmacologica Sinica, vol. 41, no. 10, pp. 1301-1309, 2020.

[53] Y. Tan, D. Mui, S. Toan, P. Zhu, R. Li, and H. Zhou, "SERCA overexpression improves mitochondrial quality control and attenuates cardiac microvascular ischemia-reperfusion injury," Molecular Therapy-Nucleic Acids, vol. 22, pp. 696-707, 2020.

[54] L. Teng, Q. Meng, J. Lu et al., "Liquiritin modulates ERK- and AKT/GSK- $3 \beta$-dependent pathways to protect against glutamate-induced cell damage in differentiated PC12 cells," Molecular Medicine Reports, vol. 10, no. 2, pp. 818-824, 2014.

[55] P. Liu, Y. Cai, J. Zhang et al., "Antifungal activity of liquiritin in Phytophthora capsici comprises not only membranedamage-mediated autophagy, apoptosis, and $\mathrm{Ca}^{2+}$ reduction but also an induced defense responses in pepper," Ecotoxicology and Environmental Safety, vol. 209, Article ID 111813, 2021.
[56] V. T. Thu, H. K. Kim, L. T. Long et al., "NecroX-5 exerts antiinflammatory and anti-fibrotic effects via modulation of the $\mathrm{TNF} \alpha / \mathrm{Dcn} / \mathrm{TGF} \beta 1 / \mathrm{Smad} 2$ pathway in hypoxia/reoxygenation-treated rat hearts," The Korean Journal of Physiology \& Pharmacology, vol. 20, no. 3, pp. 305-314, 2016. 